\title{
Resultados de las prospecciones geomagnéticas desarrolladas en el oppidum de Monte Bernorio (Pomar de Valdivia, Palencia)
}

\author{
Results of the geomagnetic surveys developed at the oppidum of Monte Bernorio (Pomar \\ de Valdivia, Palencia)
}

Jesús F. Torres-Martínez ${ }^{\mathrm{a}}$, Felix Teichner ${ }^{\mathrm{b}}$, Manuel Fernández-Götz $^{\mathrm{c}}$ y Javier Vallés Iriso ${ }^{\mathrm{d}}$

\section{RESUMEN}

Los trabajos de prospección geomagnética desarrollados en el oppidum de Monte Bernorio en los años 2007 y 2008 han ofrecido importante información sobre la estructura del asentamiento, sus sistemas de fortificación y las necrópolis asociadas. Además, los resultados han permitido mejorar la planificación de las campañas de intervención, ejecutando las excavaciones de un modo más eficiente y optimizando los recursos empleados. Este artículo presenta, por primera vez, un resumen de los resultados de estas prospecciones geomagnéticas realizadas en el marco de una colaboración internacional entre equipos científicos de España y Alemania.

\begin{abstract}
The geomagnetic surveys carried out at the oppidum of Monte Bernorio in the years 2007-2008 have offered important insights into the structure of the settlement, its fortification system and the associated cemeteries. Moreover, the results have improved fieldwork planning, allowing the excavations to be undertaken in a more efficient way and resources to be optimized. This article offers, for the first time, a summary of the results of these surveys, car-
\end{abstract}

ried out as the result of an international collaboration between scientific teams from Spain and Germany.

Palabras clave: Edad del Hierro; Norte Península Ibérica; Monte Bernorio; Prospección geomagnética; Urbanismo.

Key words: Iron Age; Northern Iberian Peninsula; Monte Bernorio; Geomagnetic survey; Urbanism.

\section{INTRODUCCIÓN}

El oppidum de Monte Bernorio (Pomar de Valdivia, Palencia) se extiende sobre una cima amesetada y plana de unas 28 ha, lo que lo convierte en uno de los yacimientos fortificados más extensos de la Edad del Hierro de la Península Ibérica. En los años 2007 y 2008 se emprendieron en la Zona Arqueológica sendas campañas de prospecciones geomagnéticas para la detección de estructuras en el subsuelo, dirigidas por el Prof. Dr. Felix Teichner y realizadas por un equipo de la Universidad de Marburgo (antes vinculado a la Universidad de Frankfurt am Main) en colabora-

a Dpto. de Prehistoria. Facultad de Geografía e Historia. Universidad Complutense de Madrid. C/ Prof. Aranguren s/n. 28040 Madrid. Instituto Monte Bernorio de Estudios de la Antigüedad del Cantábrico (IMBEAC). Correo e.: ketxutorres@yahoo.com

b Vorgeschichtliches Seminar, Philipps-Universität Marburg. Biegenstraße 11. 35032 Marburg. Correo e.: teichner@staff.uni-marburg.de

c School of History, Classics and Archaeology. University of Edinburgh. William Robertson Wing, Old Medical School, Teviot Place. Edinburgh EH8 9AG. Reino Unido. Correo e.: M.Fernandez-Gotz@ed.ac.uk

${ }^{\text {d }}$ Centro de Apoyo a la Investigación (CAI). Facultad de Geografía e Historia, Universidad Complutense de Madrid. C/ Prof. Aranguren s/n. 28040 Madrid. Correo e.: javall01@ucm.es

Recibido 18-I-2016; aceptado el 23-III-2016. 
ción con el equipo Monte Bernorio. Los trabajos consistieron en un estudio de magnetometría en varios sectores del yacimiento con el fin de determinar las características del subsuelo y localizar evidencias de posibles estructuras arqueológicas. Ambas campañas forman parte de un plan más amplio de intervención arqueológica que contempla practicar excavaciones en distintas áreas del yacimiento para definir la estructura urbana, económica y de relación social y establecer una estratigrafía del núcleo que sirva para desarrollar un relato histórico de la ocupación de este enclave (Torres-Martínez y Martínez 2012; TorresMartínez et al. e. p. $)^{1}$.

Las prospecciones geofísicas cubrieron varias áreas en el interior del recinto amurallado del oppidum y un sector al exterior. En la campaña del año 2007 se inició un intenso programa de prospecciones geomagnéticas en cinco zonas $(\mathrm{A}, \mathrm{B}, \mathrm{C}$, $\mathrm{D}$ y E) repartidas por el yacimiento que afectaron tanto a áreas previamente sondeadas como a otras todavía inéditas. En el año 2008 la intervención se llevó a cabo en la zona más elevada del mismo, donde las estructuras de poblamiento indígena fueron arrasadas para instalar un pequeño campamento o castellum romano (Área 1).

\section{EL MÉTODO GEOFÍSICO Y SU APLICACIÓN EN EL OPPIDUM DE MONTE BERNORIO}

Los métodos de prospección geofísica se han demostrado durante las últimas décadas como un valioso instrumento para conocer la fisonomía de los yacimientos arqueológicos, tanto para establecer su extensión y estructuración como para identificar áreas potenciales de excavación. Es cada vez más evidente que la inteligente combinación de prospecciones a gran escala y micro-sondeos diagnósticos constituye una buena alternativa a las tradicionales estrategias de excavación extensiva.

\footnotetext{
1 Para un conocimiento más en profundidad de las actuaciones en el yacimiento existe ya una bibliografía que comprende un amplio relato de sus estructuras defensivas, fases de ocupación, cultura material y proyección territorial: Torres-Martínez et al. 2011; Torres-Martínez y Martínez 2012; Torres-Martínez et al. 2012a; Torres-Martínez et al. 2012b; Torres-Martínez et al. 2013a; Torres-Martínez et al. 2013b; Torres-Martínez y Ballester 2014; Torres-Martínez y Luis 2014.
}

Este avance de la metodología arqueológica posee un claro interés económico (al reducir los costes de las intervenciones arqueológicas) y también permite conocer el patrimonio arqueológico sin destruirlo.

El equipo alemán de Geoarqueología de la Universidad de Marburgo ha tenido ocasión de evaluar la utilidad de este nuevo enfoque metodológico en la práctica arqueológica en cooperación con varios equipos locales de la Península Ibérica. Dicho enfoque se ha empleado en yacimientos con estructuras y cronologías muy diversas como la necrópolis mesolítica de Poças de São Bento (Setúbal, Portugal) en el valle del río Sado, los yacimientos mesolíticos en cueva de Alloru (Llanes, Asturias), la necrópolis megalítica de la Sierra Plana de la Babolla (Llanes, Asturias), los castros de la Edad del Hierro de Bolumburu (Zalla, Vizcaya), la famosa villa romana de La Olmeda (Pedrosa de la Vega, Palencia), o ciudades hispano-romanas como Iuliobriga (Retortillo, Cantabria), Mirobriga (Santiago do Cacém, Setúbal, Portugal), Regina (Casas de Reina, Badajoz) e Itálica (Santiponce, Sevilla) (Cepeda et al. 2009; Teichner et al. 2009; Teichner y Oberhofer 2013; Álvarez Martínez et al. 2015; Arias et al. 2015).

El método geomagnético resultó el más adecuado entre las técnicas geofísicas disponibles considerando el tipo de las estructuras arqueológicas que cabía esperar en el subsuelo de Monte Bernorio, la extensión del yacimiento y la situación del terreno. Este método se acepta, en general, como el más eficaz y rápido para obtener datos de campo en yacimientos de cierta extensión. Es un método geofísico pasivo que permite reconocer estructuras arqueológicas enterradas bajo la superficie terrestre a partir de la detección y medida de anomalías en el campo magnético terrestre (teóricamente regular) (Udías y Mezcua 1986; Witten 2006). Se obtiene una medición del gradiente superficial de la componente vertical del campo magnético normal de la tierra o amplitud $(\mathrm{Az})$ en nanoTesla (nT), cuyas modificaciones tanto positivas como negativas a partir del nivel normal (cero) evidencian la existencia de objetos magnéticos en el subsuelo de origen geológico o antrópico. La magnetización o susceptibilidad magnética más fuerte se pueden deber a la presencia de elementos férricos o de materiales que han sufrido procesos de calentamiento elevado, como concentraciones de tierra quemada, hornos

Trab. Prehist., 73, N. ${ }^{\circ}$ 2, julio-diciembre 2016, pp. 365-376, ISSN: 0082-5638

doi: $10.3989 /$ tp.2016.12180 
o artefactos que resultan de procesos de cocción (cerámica, ladrillo etc.). La susceptibilidad magnética aumenta también cuando se ha producido una acción antrópica prolongada en el subsuelo, que puede generar concentraciones de material orgánico de posible interés arqueológico, como agujeros de postes, silos, zanjas o fosas en contextos de hábitat. En cambio, los objetos sin propiedades magnéticas proporcionarán lecturas negativas.

En Monte Bernorio, se eligió un conjunto de áreas susceptibles de ser prospectadas mediante métodos geofísicos en base a la caracterización de las estructuras del oppidum de la Edad del Hierro (defensas, estructuras constructivas, edificios, espacios de necrópolis, etc.) y de época romana (campamento). La prospección tuvo lugar en septiembre de 2007 y julio de 2008 por un equipo dirigido por Félix Teichner (arqueólogo) con la asistencia de Tedda Hänsler (geofísica). Los demás co-autores del presente artículo han completado el análisis de los resultados.

Antes de iniciar las prospecciones se definieron en las Zonas A, B, C, D y E a prospectar unas cuadrículas rectangulares cuya extensión varía desde $\operatorname{los} 12$ × $20 \mathrm{~m}$ a los 30 × $50 \mathrm{~m}$ (Tab. 1) para adaptarlas a la topografía del terreno. Las esquinas de estas cuadrículas se georreferenciaron en el sistema de referencia geodésico oficial en España, European Terrestrial Reference System 1989 en proyección UTM zona 30N (ETRS89 UTM 30N, EPSG: 25830). El área prospectada total cubrió $13.090 \mathrm{~m}^{2}$ y se concentró en espacios en llanura sin apenas arbolado. En las prospecciones de 2007 y 2008 se utilizó un Fluxogatemagnetómetro modelo FEREX 4.032. Este instrumento, desarrollado por la empresa Foerster, consta de tres sondas en disposición horizontal (Fig. 1), distanciadas 0,5 $\mathrm{m}$. La precisión más elevada es de $0,3 \mathrm{nT}$ en una media de 128 mediciones. Este magnetómetro se combinó con un disparador (trigger) externo tipo ST1, capaz de hacer mediciones independientes, siempre a intervalos iguales de tiempo. En base a la experiencia previa adquirida, el disparador se configuró para que tomara medidas a intervalos de $0,25 \mathrm{~m}$ (valor medio). Finalmente, tras delimitar las áreas de prospección y montar y calibrar el magnetómetro, se establecieron líneas a intervalos de $1,5 \mathrm{~m}$, prospectadas según el llamado ox-turning style, que consiste en que, una vez acabada una línea, se gira $180^{\circ}$ y se realiza la siguiente en sentido inverso. Considerando la distancia en-

\begin{tabular}{|c|c|c|c|}
\hline Áreas & Cuadrícula & $\mathbf{m}^{2}$ & Total $\mathrm{m}^{2}$ \\
\hline $\begin{array}{c}\text { Zona A } \\
\text { "Cima de la colina" }\end{array}$ & $\begin{array}{l}\mathrm{A} 1=30 \times 50 \mathrm{~m} \\
\mathrm{~A} 2=30 \times 45 \mathrm{~m} \\
\mathrm{~A} 3=30 \times 50 \mathrm{~m} \\
\mathrm{~A} 4=30 \times 50 \mathrm{~m}\end{array}$ & $\begin{array}{l}1.500 \mathrm{~m}^{2} \\
1.350 \mathrm{~m}^{2} \\
1.500 \mathrm{~m}^{2} \\
1.500 \mathrm{~m}^{2}\end{array}$ & $5.850 \mathrm{~m}^{2}$ \\
\hline $\begin{array}{c}\text { Zona B } \\
\text { "Muro de tierra" }\end{array}$ & $\mathrm{B}=32 \times 50 \mathrm{~m}$ & & $1.600 \mathrm{~m}^{2}$ \\
\hline $\begin{array}{l}\text { Zona C } \\
\text { "Terraza sur" }\end{array}$ & $\begin{array}{l}\mathrm{Cl}=12 \times 40 \\
\mathrm{C} 2=12 \times 40 \\
\mathrm{C} 3=12 \times 40 \\
\mathrm{C} 4=12 \times 20\end{array}$ & $\begin{array}{l}480 \mathrm{~m}^{2} \\
480 \mathrm{~m}^{2} \\
480 \mathrm{~m}^{2} \\
240 \mathrm{~m}^{2}\end{array}$ & $1.680 \mathrm{~m}^{2}$ \\
\hline $\begin{array}{l}\text { Zona D } \\
\text { "Terraza" }\end{array}$ & $\begin{array}{l}01=12 \times 40 \\
02=12 \times 40\end{array}$ & $\begin{array}{l}480 \mathrm{~m}^{2} \\
480 \mathrm{~m}^{2}\end{array}$ & $960 \mathrm{~m}^{2}$ \\
\hline \multirow[t]{2}{*}{$\begin{array}{l}\text { Zona E } \\
\text { "Necrópolis' }\end{array}$} & $\begin{array}{l}\mathrm{E} 1=30 \times 50 \mathrm{~m} \\
\mathrm{E} 2=30 \times 50 \mathrm{~m}\end{array}$ & $\begin{array}{l}1.500 \mathrm{~m}^{2} \\
1.500 \mathrm{~m}^{2}\end{array}$ & $3.000 \mathrm{~m}^{2}$ \\
\hline & & Total & $13.090 \mathrm{~m}^{2}$ \\
\hline
\end{tabular}

Tab. 1. Áreas donde se desarrolló la prospección geomagnética en el interior del oppidum de Monte Bernorio en el año 2008 con las superficies parciales y totales prospectadas.

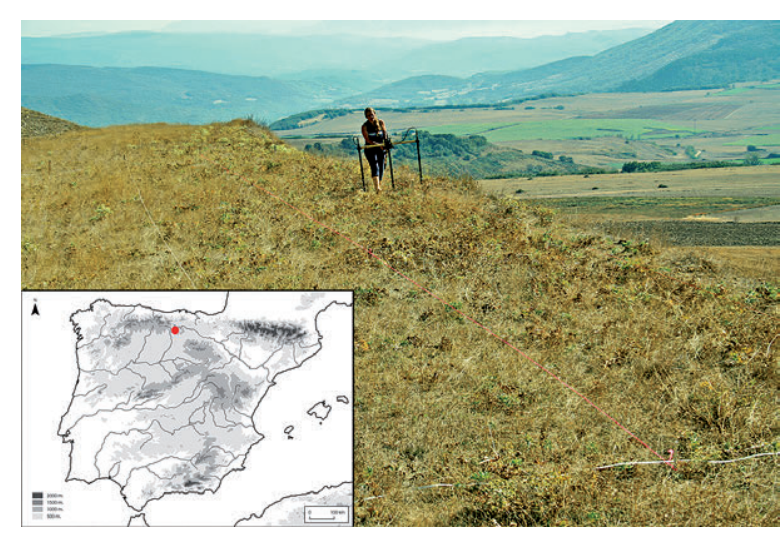

Fig.1. Trabajos de prospección geomagnética en el interior del oppidum de Monte Bernorio a cargo de Tedda Hänsler (fotografía Equipo Monte Bernorio).

tre los sensores y el intervalo establecido en el disparador para la toma de datos, se generó una malla de medidas de $0,25 \mathrm{~m}$ en el sentido de la marcha y de $0,5 \mathrm{~m}$ de ancho.

El magnetómetro almacenó tres coordenadas relativas $(\mathrm{X}$ e $\mathrm{Y}$ ) para la posición relativa de cada medida tomada en la cuadrícula, y un tercer valor relativo a la susceptibilidad magnética del punto, medido en nanoTeslas (nT). Después todas las coordenadas fueron exportadas a un documento en formato *.txt. Estos datos se procesaron con los programas Magprolight4Surf y Surfer. El 
primero homogeneiza los datos de cada línea de medidas a través de la aplicación de un filtro de la media. El segundo permite visualizar los datos ya procesados, aplicando el mismo filtro (comparando siempre 5 x 3 valores) y una interpolación parcial. Las imágenes de la prospección magnética creadas con Surfer muestran por convención los valores positivos (nT alto) en blanco y los valores negativos en negro. En un último paso, los magnetogramas georreferenciados se exportaron en formato geotiff para su inclusión sobre el mapa topográfico del yacimiento, existente en Autocad (Fig. 2).
La aplicación de este método proporcionó imágenes muy interesantes donde se observan anomalías en las cinco zonas prospectadas en Monte Bernorio. Las alteraciones medidas en el campo magnético natural de las mismas suelen corresponder a restos arqueológicos en el subsuelo, interpretables con facilidad como zanjas, fosos, estructuras de habitación y áreas de actividad humana. En otros casos, responden a estructuras naturales o intervenciones humanas modernas. No obstante, también las alteraciones antrópicas detectadas pueden pertenecer a diversos períodos históricos e incluso a intervenciones arqueológicas previas.

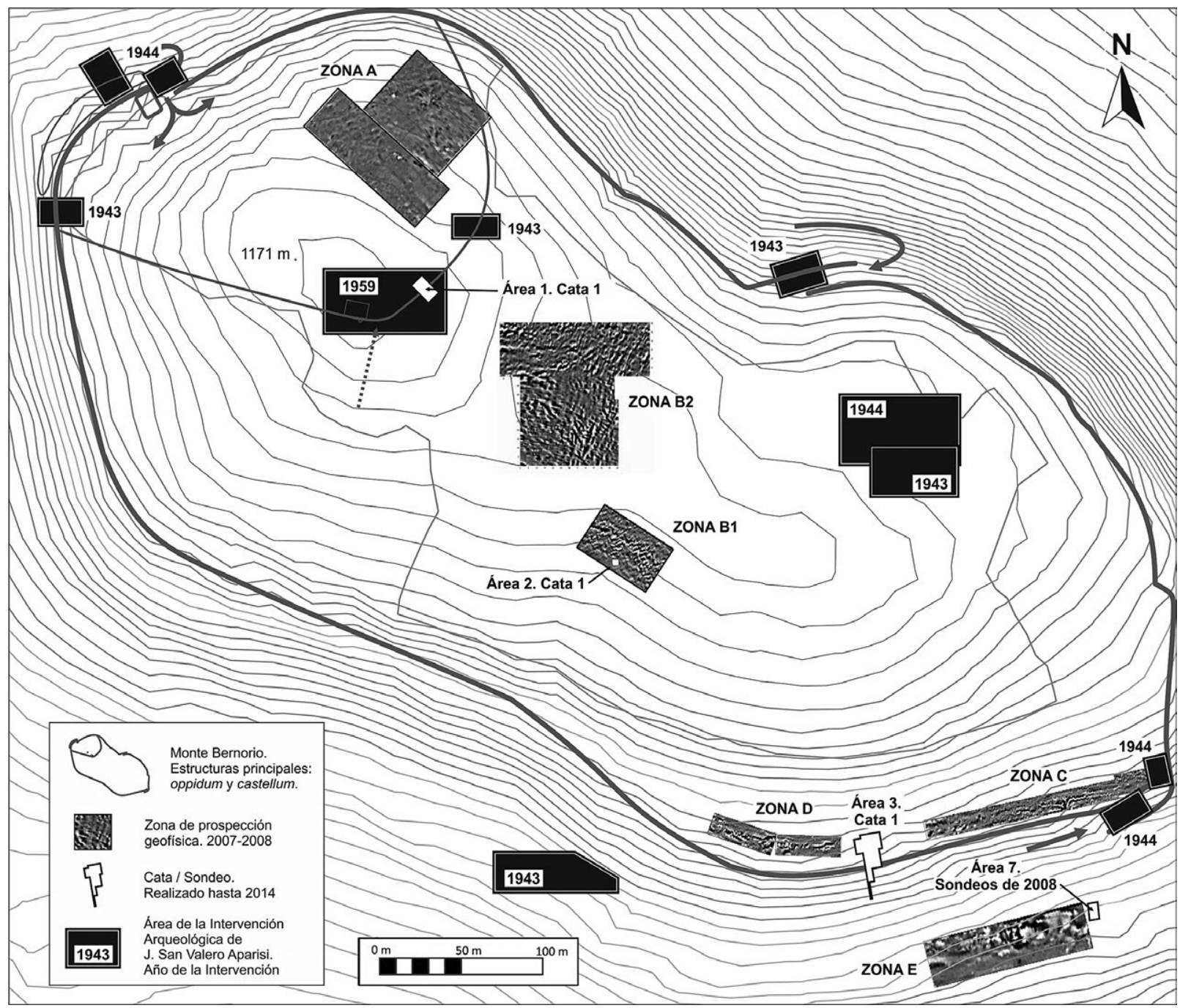

Fig. 2. Oppidum de Monte Bernorio. Plano de conjunto mostrando las áreas excavadas por San Valero (1943-1959), las excavaciones recientes del proyecto Monte Bernorio (2004-2014) y las zonas A, B, C, D y E prospectadas geomagnéticamente (imagen del Equipo Monte Bernorio).

Trab. Prehist., 73, N. ${ }^{\circ} 2$, julio-diciembre 2016, pp. 365-376, ISSN: 0082-5638 doi: $10.3989 /$ tp. 2016.12180 


\section{Zona A (acrópolis, Fig. 3)}

La Zona A se sitúa en la parte más elevada de la montaña, en lo que se venía denominando como acrópolis del Bernorio. Las excavaciones en el año 2004 demostraron que, en realidad, se trataba de un castellum o "fuerte romano" construido tras la destrucción del oppidum (Torres-Martínez et al. 2011: 137-143). Las prospecciones cubrieron una zona del sector interno del castellum romano, relativamente alejada de la estructura conocida como "El Castillete".

En la denominada Zona A (Fig. 3) se observan una serie de alineaciones que se han interpretado con trazos de color negro en los gráficos. Estas alineaciones podrían corresponder a muros con diferentes orientaciones. En este sentido, los valores de nT homogéneos y elevados deberían ser resultado de la acumulación de piedra o de material orgánico, ambos de origen antrópico. Otra alineación podría corresponder a una canalización o, con más probabilidad, un muro de gran tamaño, interpretable tal vez como un refuerzo de muro de terraza para la posterior urbanización del área. La zona marcada con una red de cuadrículas presenta anomalías desordenadas interpretadas como zonas de acumulaciones de derrubios o escombreras, dado el elevado nivel de ruido observable en los datos. Es probable que existan elementos constructivos aunque los resultados no se hayan logrado interpretar como tales. En la zona central dos fuertes anomalías, sin una morfología clara podrían ser zonas quemadas o de hornos.

Estos resultados identificaron estructuras cuadrangulares, orientadas en sentidos distintos, que podrían indicar varias fases de ocupación. Al menos dos están confirmadas por los resultados del sondeo en la acrópolis (Fig. 2, Área 1, Cata 1). La prolongada ocupación de este espacio, unida a la construcción de "El Castillete", indicaría un establecimiento que iría más allá de la duración de las Guerras Cántabras (Torres-Martínez et al. 2011: 140-141, 143). Estas estructuras recuerdan los barracones legionarios documentados por E. Peralta Labrador en sus excavaciones de los yacimientos de Cildá (Corvera de Toranzo y Arenas de Iguña, Cantabria) y La Espina del Gallego (Corvera de Toranzo y Arenas de Iguña, Cantabria) que pueden estar formados a partir de varias estructuras cuadrangulares adosadas (Peralta 1999: 220-229, figs. 1-3, 5, 2003: 275, 301-315, fig. 156, 2004: 119).

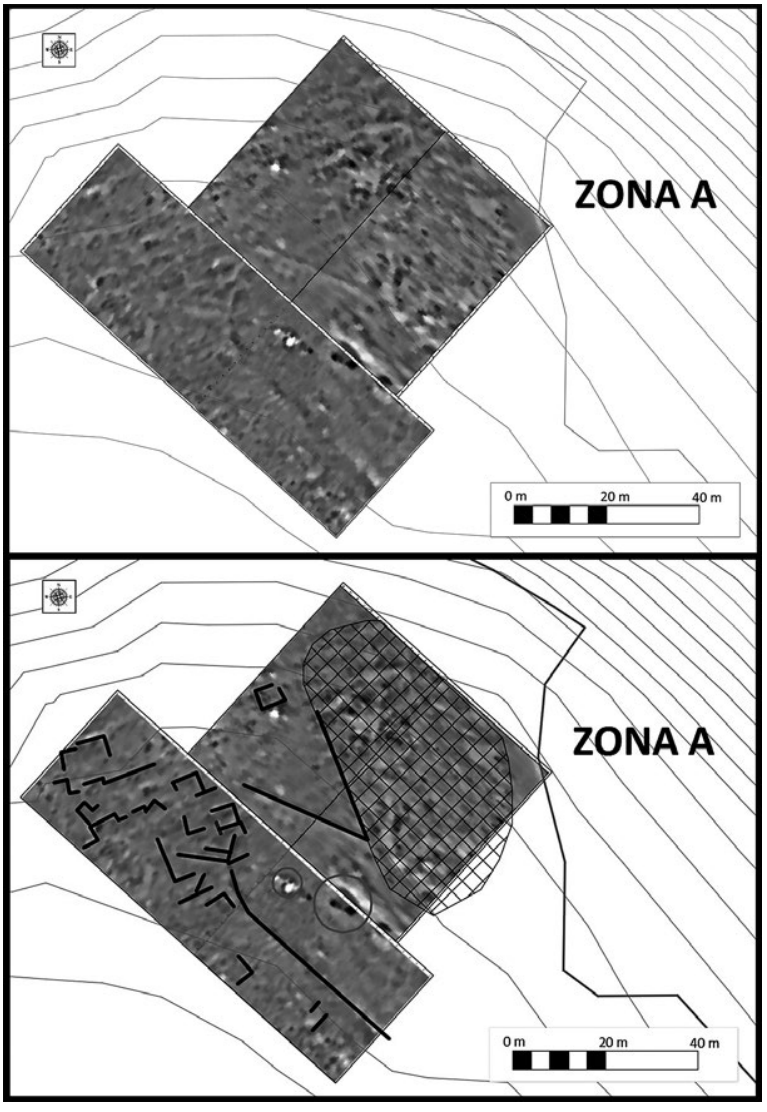

Fig. 3. Arriba imágenes obtenidas en la Zona A de la acrópolis del Bernorio, en realidad, un castellum o "fuerte romano" construido tras la destrucción del oppidum. Abajo unas posibles estructuras cuadrangulares interpretables como construcciones romanas. Se observan dos fuertes anomalías (con altas diferencias de nT/geomagnética) sin una morfología clara (señalizadas con círculos grises), pero podría tratarse de zonas quemadas o de hornos (imágenes de F. Teichner y J. Vallés Iriso).

\section{Zona B (interior del oppidum, Figs. 4 y 5)}

Los trabajos de prospección geomagnética en la Zona B, en el interior del oppidum, se ubican en áreas donde apenas se han realizado campañas de excavación ${ }^{2}$. Por lo tanto, nos permiten

\footnotetext{
${ }^{2}$ La excepción es la Cata 1 del Área 2 (2 x 2 m, Fig. 2), excavada en 2004 y localizada en los límites de la Zona B1 de las prospecciones geomagnéticas (realizadas a posteriori), fuera de donde se detectaron las anomalías. En la cata se descubrieron diversos materiales de la Edad del Hierro, pero los menos de 8 $\mathrm{cm}$ de potencia estratigráfica conservada antes de llegar al nivel geológico no permitieron localizar estructuras.
} 
'asomarnos' a áreas inéditas y comprobar si la información obtenida es coherente con lo que sabemos de las zonas ya excavadas.

En las prospecciones de la Zona B1 se observan fuertes anomalías sin alineación aparente que permiten diferenciar tres zonas (Fig. 4). La zona más al norte presenta una granulometría moderada sin alineaciones. La zona central tiene mayores anomalías y alguna alineación aparente, aunque no muy clara. En la zona sur las pocas anomalías indican una ausencia de elementos constructivos.

Estos resultados concuerdan con las prospecciones visuales realizadas en el interior del yacimiento, según las cuales, la práctica totalidad del área interior del oppidum parece estar distribuida en terrazas separadas por escalonamientos naturales reforzados, en muchos casos, con muros de

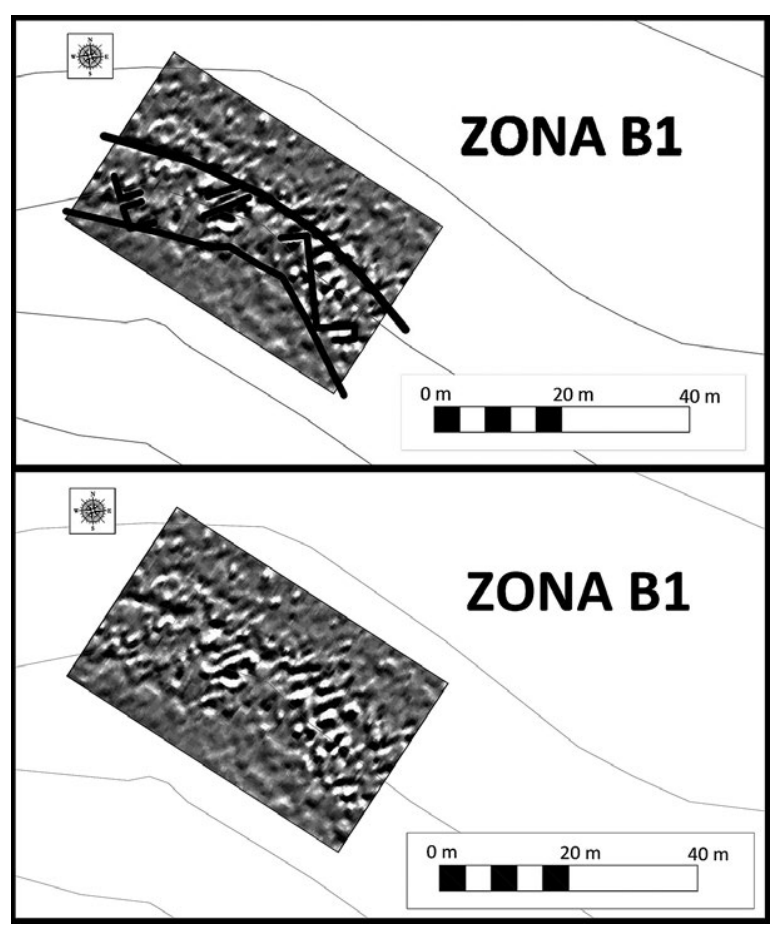

Fig. 4. Oppidum de Monte Bernorio, Zona B1. Arriba vista de los resultados obtenidos. Abajo se interpretan las posibles estructuras detectadas. Se diferencian tres zonas. La más al norte presenta una granulometría moderada sin alineaciones. La zona central, con mayores anomalías, muestra alguna alineación aparente, aunque no muy clara. Las pocas anomalías de la zona sur indicarían la ausencia de elementos constructivos. Los contrastes altos de blanco/negro de la geomagnética (arriba) pueden indicar estructuras quemadas, o bien muros con derrumbe al lado (imágenes de F. Teichner y J. Vallés Iriso). obra. El espacio interior de estas zonas aterrazadas parece estar ocupado por construcciones dispuestas de modo agrupado, pero no adosado, dejando espacios para el paso entre éstas.

También debemos señalar que durante la campaña geomagnética de 2008 se identificaron indicios de una gran construcción rectangular en la Zona B2 (Fig. 5). Esta edificación, al menos de treinta metros de lado, podría estar en relación bien con otra construcción de un tamaño un poco menor, incluida el ese mismo área, bien con una fase anterior o posterior. En todo caso estas grandes construcciones podrían estar indicando lo que podríamos denominar un "área pública", tal vez similar a las documentadas recientemente en otros oppida de la Europa centro-occidental (Fernández-Götz 2014). La existencia de áreas públicas con grandes edificaciones o estructuras

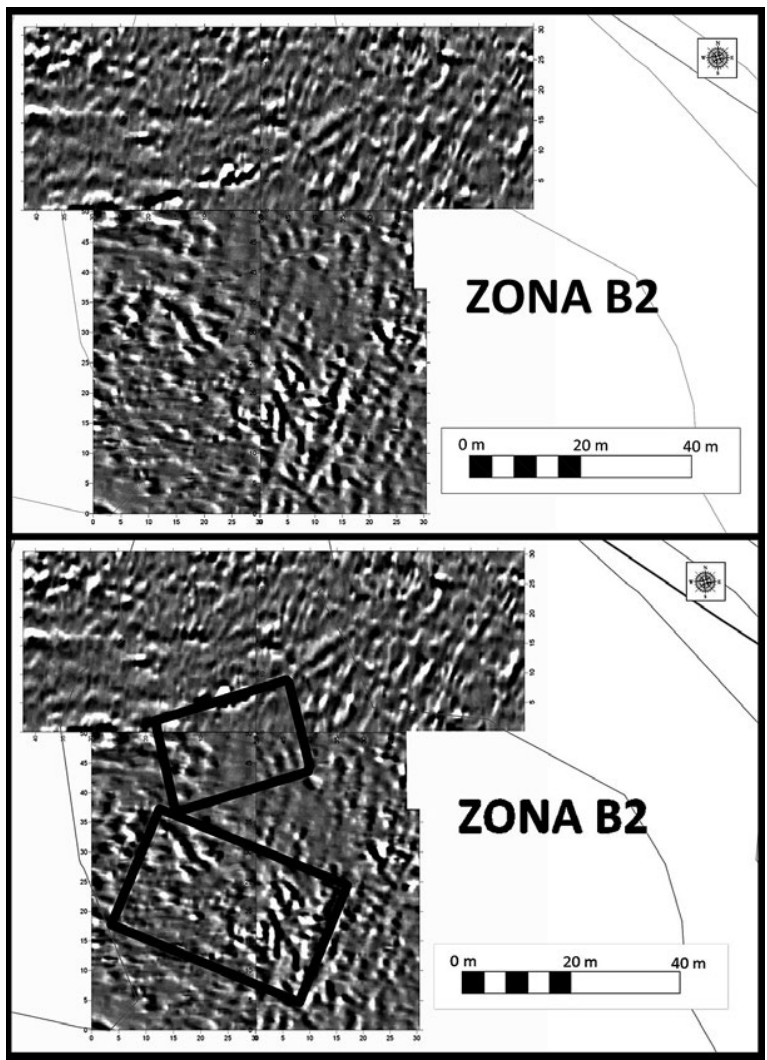

Fig. 5. Oppidum de Monte Bernorio, Zona B2. Arriba se ven los resultados obtenidos en la prospección del año 2008. Abajo se evidencia una gran construcción de forma rectangular de una treintena de metros de lado y otra muy próxima de un tamaño un poco menor (imágenes de $\mathrm{F}$. Teichner y J. Vallés Iriso). 
interpretables como edificios para reuniones colectivas, almacenes comunales o zonas de talleres resulta coherente con el carácter de oppidum del yacimiento, como centro de agregación social, pero también de actividades económicas.

\section{Zonas C y D (terraza sur, Fig. 6)}

Las Zonas C y D se sitúan en una terraza asociada a la muralla próxima a la puerta sur del oppidum. Aquí las excavaciones se vienen desarrollando desde el año 2004 en que se localizó este tramo de muralla. En este área conocemos una secuencia de ocupación relativamente larga ya que los materiales se remontan al menos al inicio de la Primera Edad del Hierro. Una reestructuración provocó una intensa remoción del espacio interior de la terraza, documentada al menos por tres niveles que llegan hasta el momento final de destrucción del oppidum por el ejército romano (Torres-Martínez et al. 2012a: 142-145; TorresMartínez et al. 2013b: 29-33).

A partir de los trabajos de excavación sabemos que la planta de las edificaciones tiene probablemente una tendencia elíptica en las fases más antiguas y rectangular con esquinas redondeadas en las fases más recientes, lo que es coherente con los resultados de las prospecciones geomagnéticas. Están cimentadas en piedra, en algunos casos mediante un calzado de losas y en otros con piedras de mediano y pequeño tamaño agrupadas con barro apisonado en lo que parece ser un acondicionamiento, tal vez en una zanja. A veces se amortizan dentro de la obra materiales reciclados como fragmentos de cerámicas, de huesos grandes o de molinos de mano.

Los muros, de manteado de barro mezclado con paja y elementos vegetales, se construían a partir de una estructura de postes y un entretejido de varas (zarzo). Una capa de enlucido, a base de arcilla más depurada, cubría los muros formando una superficie lisa y homogénea. Esta capa estaba recubierta, a su vez, de una especie de estucado fino, pintado en tonos marrones, amarillentos y blancos. Uno de los fragmentos de enlucido de pared recuperados tenía parte de unos signos o figuras en ocre. El barro empleado parece provenir de las vetas arcillosas del propio subsuelo del yacimiento y probablemente también de otras zonas de la montaña. Es muy posible que se produjera una continua reutilización de los materiales procedentes de las viviendas deterioradas lo que en muchos casos no facilita la identificación de los distintas secuencias de ocupación. Una gran parte de esta información proviene de los restos de muro cocidos en el incendio que destruyó el asentamiento (Torres-Martínez y Martínez 2012: 16-36).

En este mismo sector de la terraza y en las inmediaciones del área excavada las prospecciones geomagnéticas en las Zonas C y D se destinaron a determinar la densidad de la ocupación y su trama constructiva. En ambas destaca sobre otros indicios una fuerte anomalía con una cierta alineación y continuidad que podría tratarse de un muro o muralla de cierta entidad. En zonas puntuales y localizadas una serie de anomalías de forma cuadrangular podrían estar indicando una construcción de cimentación potente o bien una base de torreón (Fig. 6). Estas estructuras formando grandes concentraciones de materiales "duros" no excluyen que hubiera otros niveles con restos de construcciones. Como ya hemos explicado, los restos de edificaciones excavadas hasta el momento poseen una cimentación somera de piedras y alzados de tierra, por lo que es muy difícil que aparezcan nítidamente en la prospección geofísica. No obstante los resultados sugieren cimentaciones de edificaciones y estructuras que parecen distribuirse sin orden aparente.

Es interesante la posible existencia de una antigua línea de muro de contención o muralla subyacente en la terraza. En 2014 se han excavado hasta el suelo geológico dos cuadros de $2 \mathrm{~m}^{2}$, que forman un transecto desde la cara interna de la muralla hasta la base geológica de lo que creemos era el límite de la terraza "anterior". Ello ha permitido constatar un acondicionamiento artificial de la terraza, una verdadera obra monumental, observable asimismo en los resultados de las prospecciones, que la amplía al usar la muralla como muro de contención de un gran relleno de materiales. En dicho nivel de relleno se han localizado materiales pertenecientes a la I y II Edad del Hierro. En este sector no se ha identificado, por el momento, ninguna estructura interpretable como resto de una antigua línea de muralla, pero es evidente que ésta podría haber existido. Dado que aún hay potencia estratigráfica en una gran parte de la zona en excavación, no es descartable que los 


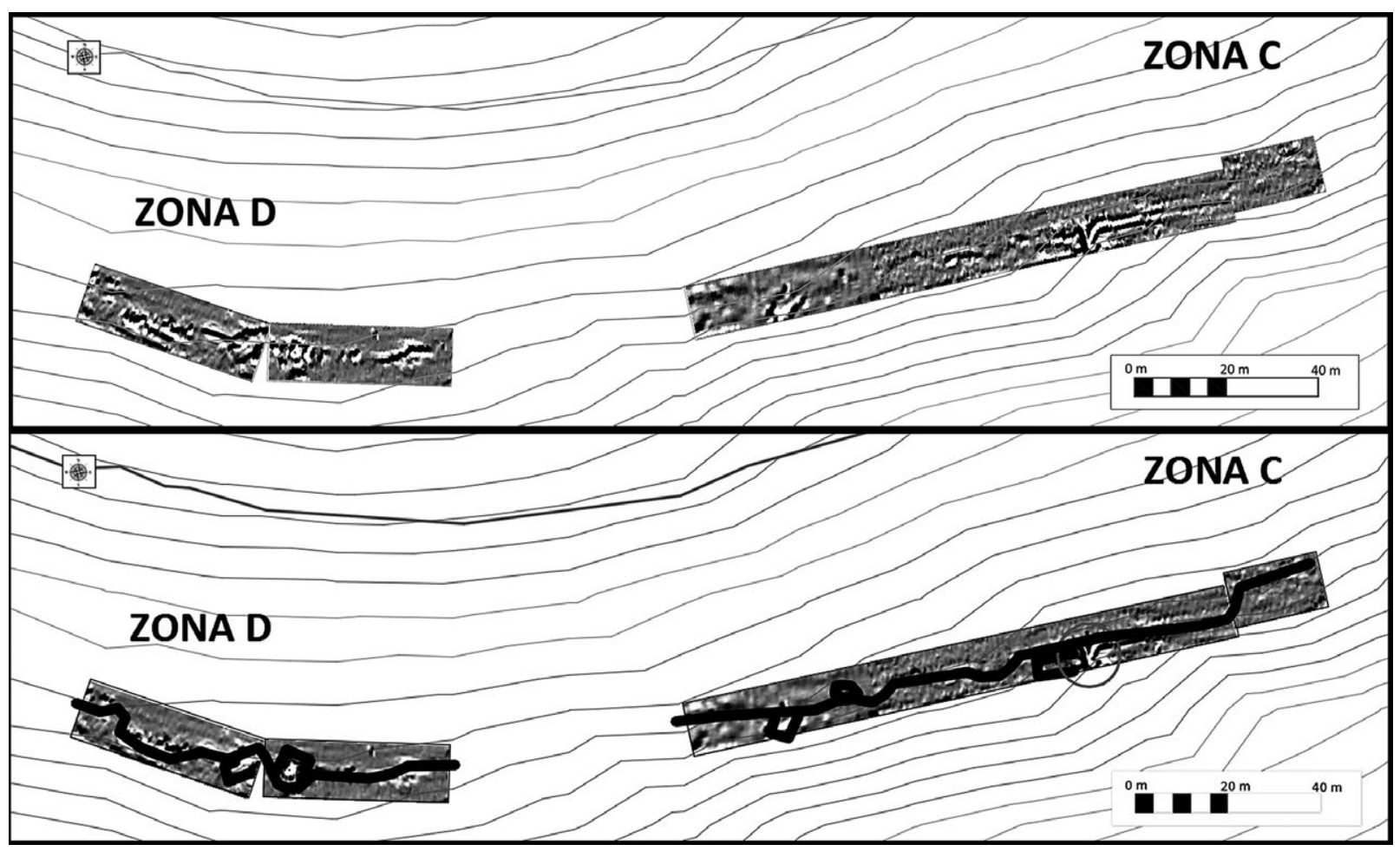

Fig. 6. Oppidum de Monte Bernorio, Zonas C y D. Arriba se muestran los resultados obtenidos. Abajo se interpretan las posibles estructuras detectadas. Se aprecia una fuerte anomalía con una cierta alineación y continuidad por lo que podría tratarse de un muro o muralla de cierta entidad. En zonas puntuales y localizadas se observan una serie de anomalías de forma cuadrada que podría ser una estructura adosada o una base de torreón. La línea con valores de magnetismo alto aparece en negro (arriba) y se interpreta como un muro (imágenes de F. Teichner y J. Vallés Iriso).

restos de esta estructura puedan ser localizados en próximas campañas.

También son destacables los indicios de posibles estructuras de tipo torre adosadas a la línea de muralla. A veces aparecen muy al interior de la terraza, por lo que parecen asociados más a una posible línea antigua amortizada que a la actual. Pero, en las inmediaciones de la puerta sur, una de estas construcciones cuadrangulares sí parece asociada a la línea exterior y a la zona final de la rampa de acceso. Toda la puerta sur está arrasada casi por completo en la actualidad al haber servido tradicionalmente como cantera; no obstante, aún conserva los restos de la cimentación de una larga rampa que se encaja en una estrecha entrada acondicionada con grandes bloques de piedra inmediatamente debajo de los acantilados donde se sitúa la muralla. Este acceso terminaba en una pronunciada rampa de diseño acodado.

Existían al menos otras dos puertas más con caminos de acceso acondicionados. En la puerta noroeste y la puerta norte todavía es posible identificar restos de las fortificaciones que las defendían. La estructura defensiva de la puerta norte se establece a partir de un largo estrechamiento formado por las líneas paralelas de la muralla. La de la puerta noroeste era una estructura de tipo torre, de planta aparentemente cuadrangular y adosada a la línea de muralla por su cara interior, que dominaba lo que pensamos puede ser la zona de acceso. Esta se producía, como en el caso de la puerta sur, por medio de una rampa con diseño acodado, que penetraba por el vano situado entre dos tramos paralelos de la muralla.

\section{Zona E (necrópolis, Fig. 7)}

La terraza donde se emplaza una de las necrópolis del Bernorio y la única excavada arqueológicamente es otro sector con resultados muy in- 
teresantes. R. Moro, capataz de las excavaciones arqueológicas de Antonio López y López, fue el primer excavador en 1890. El Marqués de Comillas, con intereses en la minería del carbón del norte de Palencia, se las encargó a R. Moro para obtener materiales arqueológicos en Monte Bernorio. R. Moro excavó en la acrópolis del yacimiento $\mathrm{y}$ tal vez en otras áreas, sin apenas resultados y posteriormente se dirigió a la necrópolis (Moro 1891; Navarro 1939: 164-172). En la terraza ahora conocida como la "necrópolis del Bernorio" encontró los puñales tipo "Monte Bernorio" y otros materiales que formaban parte de los ajuares que contenían los túmulos funerarios, datados entre los momentos finales del siglo IV y el siglo III a.C. (Moro 1891: 432-437; Cabré 1931: 222-241, fig. 4 y láms. I, IX-XI; Cabré y Cabré 1933: 42-43; Navarro 1939: 164-172; Schüle 1969; Barril 1995a: 408, 1995b, 1999: 46-51).

J. San Valero Aparisi efectuó las primeras excavaciones arqueológicas sistemáticas en Monte Bernorio en 1943, continuadas en 1944 y 1959. La necrópolis se excavó en 1943 con la ayuda de lugareños para tratar de localizar la intervención de R. Moro. A $1,5 \mathrm{~m}$ de profundidad localizaba "seis u ocho" túmulos. Varios estaban alterados por dicha intervención y otros estaban aparentemente vacíos, pero en dos encontró ajuares intactos. J. San Valero (1944: 28-33, 1960) documentó las estructuras y sus materiales y los publicó, describiendo los túmulos como un amontonamiento de piedras dispuestas ordenadamente alrededor de la tumba con el ajuar, compuesto por puñales Monte Bernorio, puntas de lanza y tahalíes. Todo aparecía recubierto por una losa de mayor tamaño y, por su apariencia, denominaba estos túmulos "mesas de roca". Alrededor de las estructuras se localizaron abundantes fragmentos de materiales metálicos quemados. Estas toscas estructuras tumulares se construyeron en contacto con la base caliza del suelo y es probable que estuvieran cubiertas por un amontonamiento de tierra (San Valero 1944: 28-33, 45-47, láms. VI y VII).

En el año 2004 se localizó en la misma terraza, pero mucho más al este, una zona con abundantes materiales arqueológicos, en su mayor parte cerámicas, con algunos fragmentos de piezas de gran calidad. Los hallazgos se distribuían por una amplia superficie de tendencia circular y ligeramente elevada que sugería la existencia de un túmulo de tierra de gran tamaño degradado por las labores agrícolas. También había indicios de actividad de expoliadores y noticias de que en ese lugar se habían obtenido algunos materiales metálicos, al parecer restos de armas.

En las excavaciones de 2007 y 2008 se localizaron, bajo una capa de tierra removida por las labores agrícolas, una serie de manchas de ceniza y carbones que estaban asociadas a hoyos rellenos de materiales quemados con tierra mezclada con cenizas y microcarbones y materiales arqueológi$\cos$ (Fig. 2, Área 7). Se recuperaron fragmentos de huesos cremados que, en principio, se identifican como humanos además de huesos de fauna. También aparecieron una cantidad relativamente importante de objetos metálicos fragmentados y con indicios de haber sido expuestos al fuego. Tenemos fíbulas, placas, agujas colgantes, restos de placas, apliques y adornos diversos en bronce, fragmentos de cadenas, remates, remaches, varillas, un fragmento de hoja de hierro y su enmangue de cuerna y algunos pequeños fragmentos cerámicos. Destacan algunos objetos de origen romano como una fíbula de tipo Alesia, remaches, tachuelas de caligae, etc. Todos los materiales se sitúan cronológicamente en la Fase final de la II Edad del Hierro.

Con estas dos campañas se consiguió excavar el espacio ocupado por el túmulo hasta el nivel geológico. Los materiales muestran que se trata de tumbas de incineración indígenas de un modelo distinto al de tipo tumular documentado en el otro extremo de la necrópolis. Además los hallazgos sitúan el desarrollo de esta necrópolis entre, al menos, el siglo IV a.C. y muy probablemente el siglo I a.C., un periodo cuando se adoptan objetos de origen romano. Hemos propuesto que esto reflejaría la participación de algunos de los habitantes del oppidum en las distintas guerras contra Roma y en las Guerras Civiles lo que llevaría a la adopción de materiales militares romanos como las tachuelas de caligae o las fíbulas tipo Alesia. Este es el final de la vida en el oppidum en los momentos inmediatamente anteriores al final violento del asentamiento en la guerra con Roma.

En el terreno contiguo al área excavada se llevaron a cabo las prospecciones geomagnéticas de la Zona $\mathrm{E}$, diferenciándose dos partes claramente (Fig. 7). En la zona norte (marcada en la imagen con una red cuadricular), una serie de anomalías pronunciadas se interpretan como estructuras tumulares a partir de los fuertes contrastes de la susceptibilidad magnética, que darían ese aspec- 


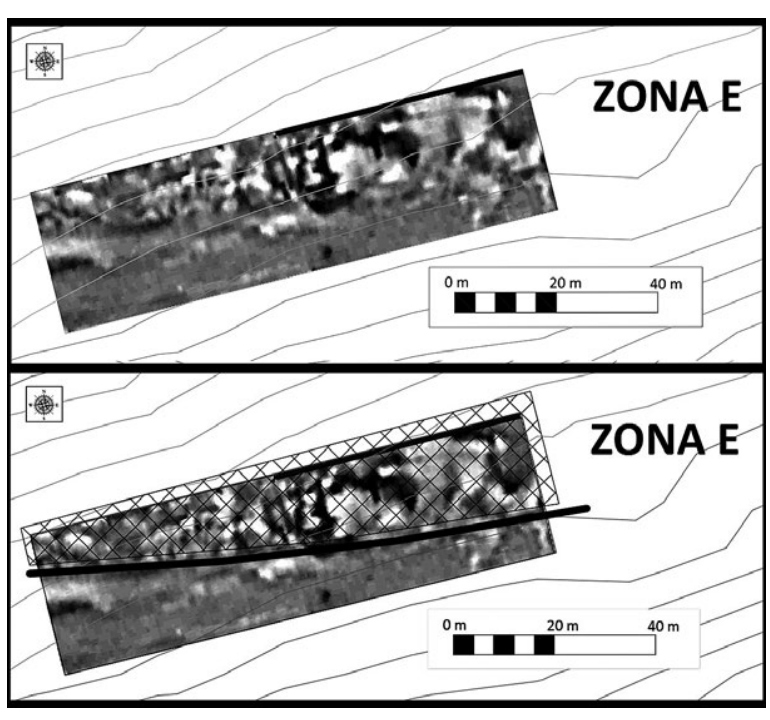

Fig. 7. Oppidum de Monte Bernorio, Zona E, necrópolis. Arriba se ven los resultados obtenidos. Abajo se interpretan las posibles estructuras detectadas. Se aprecian claramente dos zonas. La septentrional tiene muchos contrastes en el magnetismo que podrían ser indicio de una actividad antrópica conectada con una zona de acumulaciones constructivas que pueden estar arrasadas. Una alineación representada en negro podría ser un pequeño muro. En cambio en la zona sur se observa la ausencia de anomalías en una banda homogénea cuya anchura sugiere que pudiera ser un camino de acceso (imágenes de F. Teichner y J. Vallés Iriso).

to de acumulaciones constructivas arrasadas. Los resultados estarían indicando por tanto una gran concentración de posibles estructuras de piedra quizás con zonas quemadas y concentración de metales. También se ha interpretado una alineación (marcada en la imagen como línea de color negro) como un pequeño muro o más probablemente un foso de unos dos metros de anchura que pudo separar el espacio con estructuras de otro sin ellas. En esta segunda zona sur un área sin anomalías, por la anchura que presenta, podría tratarse de un camino. Lo identificamos como parte de los accesos a la puerta sur. Se sitúa como una franja de terreno despejado que discurre entre el foso que delimita la necrópolis y el borde de la terraza.

\section{CONCLUSIONES}

Los trabajos de prospección geomagnética realizados en varias áreas del oppidum de Mon- te Bernorio han logrado varios fines. El primero ha sido facilitar la planificación de los futuros trabajos de prospección y excavación, así como determinar posibles zonas de reserva en las áreas intervenidas, al servir como indicadores de las que cuentan con mayor interés y potencial arqueológico ${ }^{3}$.

También han ayudado a interpretar los posibles conjuntos de estructuras, en especial en la terraza del área sur. Tener una visión aproximada de la trama constructiva en esta extensa zona se ha traducido en una mayor seguridad a la hora de la toma de decisiones en el proceso de excavación. Además, las excavaciones efectuadas en este sector (Fig. 2, Área 3, Cata 1) han confirmado la mayoría de las informaciones obtenidas en las prospecciones geomagnéticas en las Zonas C y D localizadas en las proximidades. Las futuras intervenciones seguirán una planificación que permitirá confrontar sus resultados con los de las prospecciones geomagnéticas en otros sectores. Estas prospecciones permiten planificar cuidadosamente los trabajos a largo plazo, diseñando una estrategia de intervención adecuada a nuestra capacidad de actuación, esencial en una "Arqueología de Bajo Presupuesto" como la que se desarrolla en el yacimiento de Monte Bernorio desde hace ya más de una década. Esto permite maximizar recursos de forma eficaz. A su vez la planificación más precisa de los trabajos reduce el riesgo de exposición de zonas arqueológicamente sensibles a la actividad de los expoliadores o la incidencia de las inclemencias atmosféricas.

Como resultado, se ha decidido reiniciar los trabajos de prospección geofísica que de cara al futuro incluirán varios métodos diferentes y complementarios. El fin propuesto es avanzar en un conocimiento previo del subsuelo del yacimiento, lo más aproximado posible al de las estructuras subyacentes. Además se pretende evaluar los resultados obtenidos a partir de los distintos métodos geofísicos empleados una vez sean parcialmente excavados los distintos sectores prospectados.

\footnotetext{
3 Motivos de índole técnica impidieron analizar e interpretar los datos de las prospecciones geomagnéticas hasta 2015, siendo presentados por primera vez en el presente artículo.
} 


\section{BIBLIOGRAFÍA}

Álvarez Martínez, J. M.; Iglesias Gil, J. M.; Jiménez Chaparro, J. I.; Rodríguez Martín, F. G. y Teichner, F. 2015: "Prospecciones geofísicas en el territorio urbano de Regina Turdulorum (Casas de Reina, Badajoz)". En J. M. Álvarez, T. Nogales e I. Rodà (ed.): Centro y periferia en el mundo clásico. Actas del XVIII Congresso Internacional de Arqueología Clásica (Mérida 2013): 105-110. Mérida.

Arias, P.; Cubas, M.; Fano, M. A.; Jordá Pardo, J. F.; Salzmann, C.; Teichner, F. y Teira, L. C. 2015: "Where are the 'Asturian' dwellings? An integrated survey programme on the Mesolithic of northern Spain". Antiquity 89: 1-18.

Barril Vicente, M. 1995a: "El Castro de Los Barahones (Valdegama, Palencia): un poblado en el Alto Valle del Pisuerga". En F. Burillo (ed.): III Simposio sobre los celtiberos. Poblamiento celtibérico (Daroca 1995): 399-408. Zaragoza.

Barril Vicente, M. 1995b: "Comentarios sobre el fondo de cabaña de Monte Bernorio". En M. V. Calleja (ed.): Actas del III Congreso de Historia de Palencia (Palencia 1995): 153-173. Palencia.

Barril Vicente, M. 1999: "Dos yacimientos de la Edad del Hierro, Castro de Los Barahones y Bernorio". En J. Iglesias y J. A. Muñiz (eds.): Regio Cantabrorum. Caja Cantabria. Santander: 43-52.

Cabré Aguiló, J. 1931: "Tipología del puñal, en la Cultura de Las Cogotas". Archivo Español de Arte y Arqueología VII: 221-241.

Cabré Aguiló, J. y Cabré Herreros, M. E. 1933: "Datos para la cronología del puñal de la cultura cogotas". Archivo Español de Arte y Arqueología IX: 37-45.

Cepeda Ocampo, J. J.; Teichner, F.; Jiménez Chaparro, J. I. y Unzueta Portilla, M. 2009: "El cerco de Bolunburu. Un recinto fortificado de la Edad del Hierro en Bizkaia”. En Medio siglo de Arqueología en el Cantábrico oriental y su entorno. Congreso Internacional (Vitoria 2007): 883-894. Vitoria/Gasteiz.

Fernández-Götz, M. 2014: "Reassessing the oppida: the role of power and religion". Oxford Journal of Archaeology 33 (4): 379-394.

Moro, R. 1891: "Exploraciones Arqueológicas. Monte Cildá. Monte Bernorio. Loncejares. Arconada". Boletín de la Real Academia de la Historia XVIII. Madrid: 427-440.

Navarro García, R. 1939: Catálogo Monumental de la Provincia de Palencia. Fascículo Tercero. Partidos de Cervera del Río Pisuerga y Saldaña. Comisión Provincial de Monumentos Históricos y Artísticos. Ed. Imprenta Provincial de Palencia. Palencia.

Peralta Labrador, E. 1999: "Los castros cántabros y los campamentos romanos de Toranzo e Iguña. Prospecciones y sondeos". Las Guerras Cántabras. Fundación Marcelino Botín y Real Academia de la Historia. Santander: 201-276.
Peralta Labrador, E. 2003: Los Cántabros antes de Roma. Bibliotheca Archaeológica Hispana 5, Real Academia de la Historia. Madrid.

Peralta Labrador, E. 2004: "Cuestiones históricoarqueológicas sobre el Bellum Cantabricum y el desembarco romano en la costa cántabra". Sautuola 10: 85-130.

San Valero Aparisi, J. 1944: "Excavaciones Arqueológicas en Monte Bernorio (Palencia). Primera Campaña, 1943". Informes y Memorias 5, Comisaría de Excavaciones, Ministerio de Educación Nacional. Madrid.

San Valero Aparisi, J. 1960: Monte Bernorio. Aguilar de Campoo (Palencia). Campaña de estudio en 1959 financiada por la Diputación Provincial de Palencia. Excavaciones Arqueológicas en España 44, Ministerio de Educación Nacional y Diputación de Palencia. Madrid, Palencia.

Schüle, W. 1969: Die Meseta-Kulturen der Iberischen Halbinsel. Mediterrane und eurasische Elemente in früheisenzeitlichen Kulturen Südwesteuropas. Madrider Forschungen 3, Walter de Gruyter \& Co. Berlin.

Teichner, F.; Cepeda Ocampo, J. J.; Iglesias Gil, J. M. y Ruiz Gutiérrez, A. 2009: "La determinación del perímetro urbano de Iuliobriga (Cantabria). Prospecciones geofísicas en el sector de La Llanuca". Madrider Mitteilungen 50: 172-196.

Teichner, F. y Oberhofer, K. 2014: "Im Schatten der Colonia Emerita Augusta. Zum Stand der Forschungen in den Wohnquartieren des lusitanischen Mirobriga”. En E. Trinkl (ed.): Akten des 14 Österreichischen Archäologentages am Institut für Archäologie der Universität Graz (Graz 2012): 299-306. Viena.

Torres-Martínez, J. F. y Ballester, X. 2014: "La Tessera de Hospitalidad del oppidum de Monte Bernorio (Villarén de Valdivia, Palencia)". Paleohispánica 14: 263-286.

Torres-Martínez J. F. y Luis, S. de 2014: "Construcción del territorio y estructuras políticas. El modelo del oppidum de Monte Bernorio y otras formas de construcción territorial”. En F. Burillo y M. Chordá (eds.): VI Simposio sobre celtíberos: nuevos hallazgos, nuevas interpretaciones (Daroca 2008): 139147. Zaragoza.

Torres-Martínez, J. F. y Martínez, A. 2012: Monte Bernorio. Guía de Visita Arqueológica. Col. Montaña Palentina, Agrupación Comarcal de Desarrollo Montaña Palentina y Diputación de Palencia. Palencia.

Torres-Martínez, J. F.; Martínez, A. y Luis, S. de 2012a: "El Oppidum de Monte Bernorio. Nueve siglos de Historia". Kobie 30: 137-146.

Torres-Martínez, J. F.; Martínez, A. y Pérez, C. 2012b: "Augustan campaigns in the initial phase of the Cantabrian war and roman artillery projectiles from the Monte Bernorio oppidum (Villarén, Palencia)". Archäologisches Korrespondenzblatt 42/4: 525-542.

Torres-Martínez, J. F.; Martínez, A. y Pérez, C. 2013a: Los proyectiles de artillería romana en el oppidum 
de Monte Bernorio (Villarén, Palencia) y las campañas de Augusto en la primera fase de la guerra cantábrica". Gladius XXXIII: 57-80.

Torres-Martínez, J. F.; Martínez, A. y Serna, A. 2013b: "El oppidum de Monte Bernorio (Villarén, Palencia). Una ciudad fortificada de la Edad del Hierro en la Montaña Palentina". En Colección de Historia de la Montaña Palentina 7, Aruz Ediciones. Palencia: 11-86.

Torres-Martínez, J. F.; Fernández-Götz, M.; Martínez-Velasco, A.; Vacas, D. y Rodríguez-Millán, E. (en pren- sa): "From the Bronze Age to the Roman conquest: The oppidum of Monte Bernorio (Northern Spain)". Proceedings of the Prehistoric Society 82, 2016.

Torres-Martínez, J. F.; Serna, A. y Domínguez, S. D. 2011: "El ataque y destrucción del oppidum de Monte Bernorio (Villarén, Palencia) y el establecimiento del castellum romano". Habis 42: 127-151.

Udías, A. y Mezcua, J. 1986: Fundamentos de Geofisica. Alhambra. Madrid.

Witten, A. 2006: Handbook of Geophysics and Archaeology. Equinox Publishing. Londres. 